\title{
COMBINANDO SEU ÓCULOS FAVORITO: UM MÉTODO PARA OBSERVAR PREFERÊNCIAS DE ARMAÇÕES COM CRIANÇAS
}

\author{
lana Garófalo Chaves \\ Universidade de São Paulo - USP \\ iana@usp.br - iana_chaves@hotmail.com \\ Walter Esfrain Pereira \\ Universidade Federal da Paraíba - UFPB \\ walterufpb@yahoo.com.br \\ Cibele Haddad Taralli \\ Universidade de São Paulo - USP \\ cibelet@usp.br
}

Resumo: Dentre os usuários de óculos, o público infantil apresenta características físicas e mentais mutáveis durante seu desenvolvimento e crescimento, por isso o projeto de armações para esse grupo, demanda estudos e pesquisas aprofundadas. Além de considerar requisitos para resoluções formais e estéticas adequadas às crianças, os projetos dos óculos devem também considerar aspectos perceptivos e emocionais que despertem a afeição, tornando seu uso cotidiano prazeroso e atrativo. Esse artigo é parte de uma pesquisa que teve como objetivo principal a proposta de diretrizes para o projeto de óculos infantil. Para sua realização foi adotada a abordagem do Design Centrado no Humano, tendo como grupos pesquisados as crianças usuárias de óculos, seus cuidadores, os atendentes das óticas e os oftalmopediátras. O recorte desse artigo apresenta um método aplicado com as crianças, no qual foram apresentadas partes acabadas de armações a 144 participantes, tendo os mesmos que montar uma combinação favorita de óculos, além de escrever uma justificativa para essa escolha. As imagens dessas combinações foram analisadas de acordo com a distribuição de frequência de itens pré estabelecidos referentes a parte frontal e a haste do produto. Os resultados quantitativos possibilitaram uma discussão e análise qualitativa sobre os comportamentos e alguns padrões semelhantes entre as combinações e as preferências das atuais armações comercializadas. O conteúdo obtido com este método foi posteriormente triangulado e confrontado com os resultados dos demais métodos aplicados com os outros grupos definidos, colaborando para a definição das diretrizes. Dessa forma, esse artigo também apresenta uma síntese dos alguns dos dados triangulados que se relacionam com o conteúdo formal das armações. A experiência com esse método demonstra a possibilidade de sua aplicação em outras investigações sobre as preferências de produtos, envolvendo a participação dos usuários. 
Palavras-chave: Design Centrado no Humano, Product Experience, Design de óculos, Óculos infantil.

\begin{abstract}
Among the eyeglasses wearers, the children have physical and mental characteristics changing during its development and growth, so the frames' design for this group, demands studies and depth research. In addition to considering requirements for formal and aesthetic resolutions suitable for children, the eyeglasses design should also consider perceptual and emotional aspects that awaken affection, making everyday use more pleasant and attractive. This paper is part of a research that aimed to define guidelines for the design of children's eyeglasses. The Human Centered Design approach was used considering children who wear eyeglasses, their guardians; the optical attendants and pediatric ophthalmologists. This article presents the method applied with children in which finished parts frames were showed for 144 participants, and they had to assemble their favorite eyeglasses combination, and also writing the the reason for that choice. The combinations pictures were analyzed by distribution of frequency according to pre established items from features of front and temple. The quantitative results enabled a qualitative discussion and analysis of the behavior and some similar patterns among the combinations and preferences of current marketed frames. This method's content was later triangulated and confront with the results of other methods applied for defining the guidelines for children's eyeglasses. The experience with this method demonstrates the possibility of its application in other investigations on product preferences, involving the users participation.
\end{abstract}

Keywords: Human-Centered Design, Product Experience, Eyeglasses Design, Children eyeglasses.

\title{
1.INTRODUÇÃO
}

Os óculos se destacam por sua função social no atendimento das necessidades humanas, se considerados os indivíduos que dependem deste produto em sua condição de órtese. A origem das armações possui algumas versões e explicações diferentes e controversas (Veyrat, Blanco, Trompette, 2008; Acerenza,1997), porém é consenso que sua criação é consequência do surgimento e desenvolvimento das lentes, fato que também foi fundamental para a história de instrumentos ópticos, como lunetas e microscópios (Maldonado, 2012). Dessa forma, Brasil (2006) menciona que "o correto é afirmar que inúmeras pessoas anônimas, tanto no oriente quanto no ocidente, contribuíram gradativamente para o aperfeiçoamento desse instrumento visual".

Em mais de 700 anos de evolução, as armações auxiliam na condição visual dos indivíduos, sendo um artefato portátil, individual, que acompanha seu usuário durante todo o dia, e está presente em diversos contextos de uso, lugares e atividades. Como uma extensão do corpo e dos sentidos humanos, deve ser pensado, projetado e desenvolvido considerando requisitos centrados nas necessidades físicas e emocionais 
do homem. A relação de proximidade e apropriação dos óculos com o usuário, faz com que o mesmo seja considerado um objeto comum e familiar, Pullin (2009) acredita que o produto é bem sucedido por muitas pessoas não associarem seu uso a correção de uma deficiência. O autor apresenta uma análise positiva das armações ao compará-las com outros produtos estigmatizados que auxiliam em deficiências, a exemplo das cadeiras de rodas e aparelho auditivo, afirmando que no caso das armações a deficiência e o design estão presentes contendo muito pouco ou quase nenhum estigma social. A ausência da necessidade de que os óculos seja invisível para o usuário é apontada como uma evidência de aceitação da deficiência.

Dentre os usuários de óculos receituário, o público infantil, demanda estudos e pesquisas aprofundadas, conforme relatado por Gozlan (2007), "A orientação de óculos para crianças é uma das mais difíceis no dia a dia da óptica, porque requer competências técnicas e também psicológicas, tais quais adaptar-se à criança e orientar os pais". A metodologia de projeto para estes produtos, além da necessidade de considerar requisitos para resoluções formais e estéticas adequadas às crianças (advindas dos conhecimentos da ergonomia; antropometria; desempenho e usabilidade), também devem considerar aspectos perceptivos, subjetivos e emocionais, que despertem a afeição do público infantil, tornando o seu uso cotidiano prazeroso e atrativo. Gozlan (2007) menciona que as armações infantis não podem ser réplicas de adultos em escala menor, mas devem ser concebidas para o formato particular do rosto das crianças. Na atual bibliografia sobre as armações é observada a escassez de livros e publicações científicas e técnicas, que priorizem as especificidades do projeto de armações para o público infantil, sendo mais encontradas referências que abordam os aspectos estéticos e históricos.

Para a realização da presente pesquisa foi adotada a perspectiva da abordagem do Design Centrado no Humano (DCH) (Giacomin, 2012), na qual as questões subjetivas e emocionais dos indivíduos são consideradas no processo projetual. A abordagem do DCH considera o indivíduo principal (usuário) e os stakeholders ${ }^{1}$ envolvidos que interferem na relação do indivíduo (Krippendorf, 2000), propondo que os grupos definidos participem do processo de design através da aplicação de diferentes métodos.

A pesquisa completa teve o objetivo principal de levantar, analisar e propor diretrizes para o projeto de armações infantis, no intuito de contribuir com informações para os designers que atuam no desenvolvimento desse produto. Para a pesquisa foram considerados as crianças usuárias de óculos (entre 6 e 11 anos) e os seguintes stakeholders: os cuidadores de crianças usuárias de armação, os atendentes das óticas e os oftalmopediatras. Para cada um dos grupos foram aplicados métodos distintos e posteriormente com os resultados alcançados, esse conteúdo foi triangulado para a definição das diretrizes.

Com as crianças usuárias de óculos, foram aplicados dois métodos, o primeiro foi o Storytelling no qual trinta participantes escreveram uma história cada, com o título "Eu e meus óculos". Os textos foram analisadas pela análise do conteúdo e os resultados consistiram na organização dos dados em quatro categorias: Funcionais na qual as crianças trataram de usabilidade, sintomas do não uso do produto e sensação

\footnotetext{
${ }^{1}$ Trata-se de um grupo ou indivíduo que pode afetar ou é afetado pela realização dos objetivos da organização (Freeman, 2010).
} 
de uso do produto; Formais englobando características e cuidados com o produto; Patológico abordando as patologias oftálmicas que as acometem e Reflexivas considerando a opinião de terceiros e a aparência usando os óculos. Assim, as informações coletadas, possuíram caráter emocional, comportamental e subjetivo a respeito da relação usuário-produto.

O segundo método teve como objetivo observar questões de preferências formais em relação às armações, com a possibilidade das crianças expressarem suas preferências sem interferências encontradas no momento da escolha do produto na ótica, como por exemplo, sugestões do atendente, opinião do cuidador e até o fator financeiro. No primeiro método realizado essas questões foram abordadas superficialmente em alguns dos textos das crianças, não sendo possível indicar conclusões a este respeito.

Esse artigo apresenta um recorte da pesquisa realizada, no qual é descrito procedimentos e resultados do segundo método aplicado com as crianças, e posteriormente esse conteúdo é complementado e confrontado com outros resultados dos demais stakeholders, sobre abordagem de aspectos formais das armações infantis.

\section{MÉTODO}

O método aplicado com as crianças foi idealizado após cogitar algumas possibilidades, dentre elas a de utilizar modelos de armação em papel rígido no qual crianças poderiam recortar e customizar. Esta idéia foi descartada após a conversa com uma pedagoga, que acreditou que a atividade manual e cognitiva de natureza lúdica poderia não fornecer os resultados e objetivos pretendidos.

Assim, optou-se por utilizar armações produzidas e acabadas, que foram obtidas, parte por meio de solicitação a alguns fabricantes e parte comprada. A intenção foi conseguir o máximo de possibilidade de diferenciação de armações infantis (masculinas e femininas) com uma variação considerável de detalhes, cores, materiais e formatos. Os produtos foram desmontados, sendo desparafusadas todas as frentes das hastes, apenas os adornos e as ponteiras não foram retiradas, por acreditar que dificultaria no entendimento das crianças no momento da aplicação do procedimento de escolha.

O procedimento desse método se aproxima da proposta de Simular Experiências apresentada por Kumar (2013), que pode ser utilizada para entender como pessoas se comportam e interagem através de um experimento de interação.

Para possibilitar o acesso ao público participante da pesquisa, foi definida a sua realização em escolas, por ser um local de concentração de crianças com o perfil desejado. Inicialmente a proposta detalhada das atividades e seus objetivos, e dos procedimentos a serem realizados, com e pelas crianças foi submetida ao comitê de pesquisa da Escola de Aplicação, pertencente a Faculdade de Educação da Universidade de São Paulo para apreciação, sendo aprovadas e autorizada pela equipe técnico-pedagógica. Além da aprovação desse comitê, foi enviado para os cuidadores das crianças participantes o termo de consentimento livre e esclarecido (TCLE), solicitando a autorização para a participação individual na pesquisa. Nas demais escolas, a documentação da pesquisa foi apresentada para os coordenadores e direção e em seguida, mediante aprovação, os TCLE foram encaminhados aos cuidadores. 
Em relação a infraestrutura de apoio necessária para o procedimento, foi solicitado e justificado para as instituições participantes a necessidade de um espaço reservado, com mesa e cadeiras, e assim nos locais de aplicação, a organização do material consistiu em dispor na mesa as partes das armações separadas pelo gênero, com uma só haste de cada modelo, além de espelhos para que as crianças pudessem se olhar com as partes escolhidas posicionadas na face. Um estúdio fotográfico portátil e uma câmera no tripé também foram posicionadas previamente nas salas (Figura 1).
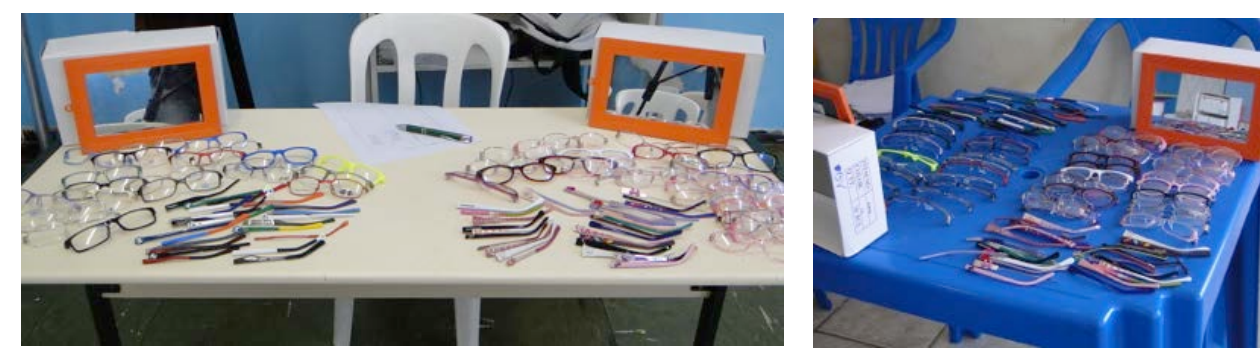

Figura 1- Aplicação do método com as partes dos óculos dispostas e separadas por gênero, em três diferentes escolas.

Fonte: autor.

O método foi aplicado, em grande parte, com uma dupla de crianças (de cada gênero) por vez, por acreditar que assim não haveria influência e não seriam escolhidas as mesmas partes. Para cada dupla de participantes, o procedimento era resumidamente explicado, sendo solicitado que os mesmos montassem uma única combinação que atendesse a dois requisitos: a que melhor agradasse esteticamente e a que eles gostariam de usar. As crianças ficaram à vontade para pegar, mexer e simular o produto na face até decidirem à combinação escolhida; com a decisão tomada as partes escolhidas eram unidas com fita adesiva; sendo a mesma fotografada no estúdio portátil. Enquanto as fotos eram realizadas cada criança respondia, em uma folha pautada, à pergunta: Por que você escolheu essa combinação de armação?, essas respostas escritas objetivou auxiliar na análise das fotos. Ao concluir a parte escrita, as crianças eram liberadas e a combinação escolhida era novamente inserida ao conjunto de peças.

O método foi aplicado em três escolas públicas na cidade de São Paulo-SP e em uma escola particular, na cidade de Campina Grande-PB, com crianças pertencentes às 1 a 5 o séries do ensino fundamental, sendo 68 meninos e 73 meninas, totalizando 141 crianças. Essa diversidade na coleta de dados teve o objetivo de proporcionar heterogeneidade entre os participantes da pesquisa, sem o intuito de gerar padrões geográficos ou sociais.

Os dados obtidos consistiram nas imagens das 141 combinações (Figura 2) que considerou os critérios de gênero, idade, além das justificativas escritas pelas crianças relacionadas a cada uma das combinações. De acordo com a variedade de partes apresentadas foram definidos os seguintes itens formais, referentes às partes frontal e haste, a serem analisados (Figura 3). 


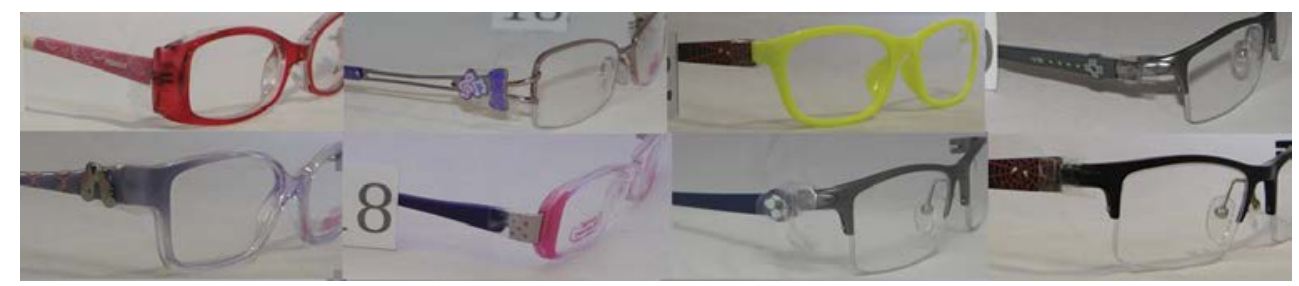

Figura 2 - Algumas das combinações escolhidas pelas crianças.

Fonte: autor

Desta forma, cada foto/combinação foi descriminada de acordo com esses itens; posteriormente com todos os dados tabulados, foi realizada a distribuição de frequência para essas variáveis qualitativas definidas. As frequências dos itens separados por gênero, possibilitou observar as incidências das escolhas sinalizando algumas tendências e serviram como base para a análise e discussão qualitativa dos resultados.
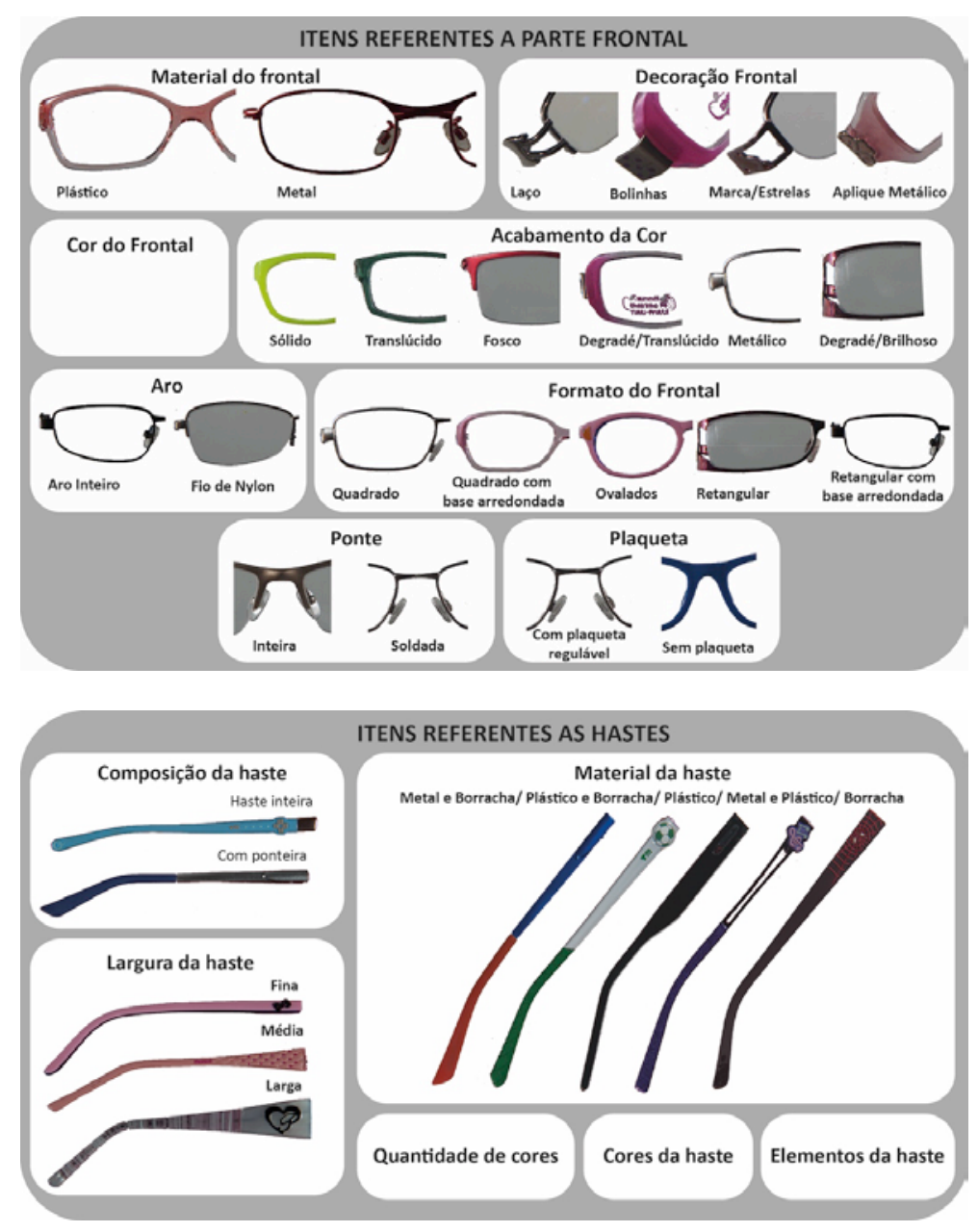

Figura 3 - Itens definidos para a análise das partes frontais e hastes das armações.

Fonte: autor

\section{RESULTADOS E DISCUSSÕES}

A aplicação do método ocorreu de forma bastante satisfatória; após a explicação as crianças conseguiam realizar a escolha da combinação sem maiores problemas. O tempo de realização da atividade por cada criança não foi registrado 
mas, de forma geral, não ultrapassou dez minutos. Alguns fatos foram observados como, quando em uma das escolas foi necessário contabilizar os possíveis participantes em sala de aula, e ao ser questionado quem usava o produto, em muitos casos as crianças não assumiram o uso, mesmo estando com os óculos na face.

Alguns comportamentos foram observados no decorrer da atividade. Diversas vezes os meninos demoravam tão quanto ou mais, que as meninas, para tomar a decisão da escolha, sendo mais minuciosos na realização da atividade. As crianças mais novas foram, no geral, as mais rápidas para tomar a decisão, ou seja, à medida que a idade aumentava a escolha era mais criteriosa e demorada.

A seguir são apresentados e discutidos os resultados obtidos separados pelos itens referentes à parte frontal do produto, seguidos dos itens referentes às hastes, finalizando com os dados das justificativas.

\subsection{Itens da parte frontal dos óculos}

O primeiro item analisado nas combinações das crianças foi o Material utilizado para o frontal dos óculos, dentre as opções de Plástico (incluindo acetato e polímeros injetados) e Metal, o total dos participantes optaram por frontais em plástico (56\%, enquanto $44 \%$ optaram por metal), sendo a preferência por ambos os materiais muito próxima.

Na preferência por gênero, as meninas preferem o plástico $(37,59 \%)$ ao invés do metal (14,18\%); ao contrário dos meninos que optam com 29,79\% por frentes em metal, ao invés de $18,44 \%$ que preferem as de plástico. Ao observar a incidência do material em relação às idades, para as meninas a escolha pelo plástico em relação ao metal é maior em todas as idades da faixa etária; tendo o metal uma maior aceitação entre as meninas mais velhas. Com os meninos, a escolha pelo Metal ocorre em todas as idades da faixa etária; entretanto, há preferência maior em relação ao plástico entre os meninos com 6 e 10 anos; com os de 7, 9 e 11 anos a preferência é semelhante para ambos os materiais; e com os de8 anos a escolha pelo Plástico sobressai em relação ao Metal. Dessa forma é possível afirmar que não há uma diferença ou totalidade acentuada entre ambos os materiais e que o plástico também tem boa aceitação do público masculino.

O item Decoração frontal dos óculos observou algumas partes femininas apresentadas que possuíam detalhes. $O$ resultado indicou que a maioria das meninas optou por frentes sem detalhe, e que apenas 22 participantes (15,6\% do total das crianças) escolheram o frontal com elemento decorativo. Ao analisar as 22 combinações com detalhes, em 20 delas a haste também possuía detalhes decorativo e nas justificativas escritas dessas combinações, em apenas uma o elemento decorativo do frontal foi citado como motivo da escolha. Desta forma, os dados indicam que a maioria das 22 meninas não considerou o detalhe frontal como sendo 0 elemento estético protagonista ou suficiente para a combinação.

Em se tratando da Cor do frontal, os dados foram diretamente analisados por separação de gênero. As principais preferências das meninas são pelo rosa seguida das combinações de branco e azul, e preto e vermelho e para os meninos a preferência é pelo azul e preto (Figura 4 ). 


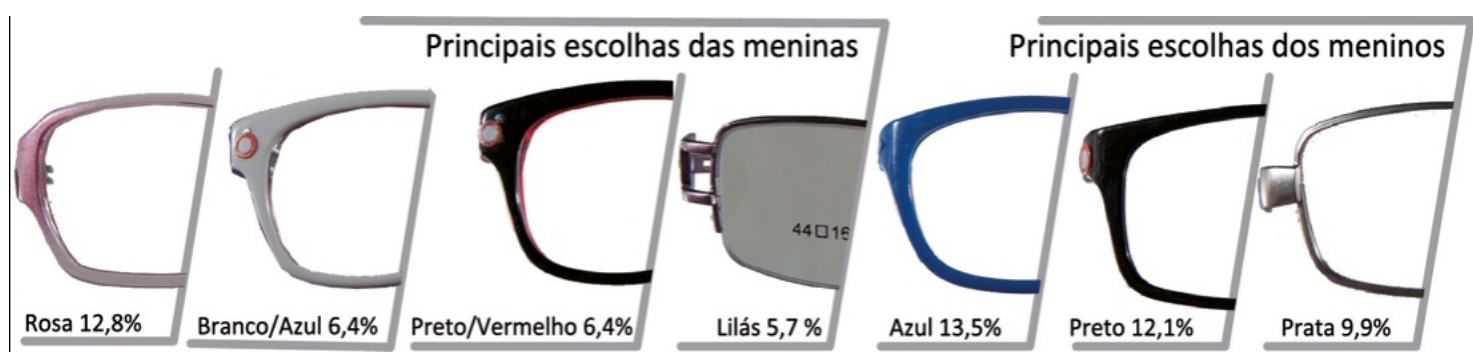

Figura 4 - Cores dos frontais com maior frequência relativa para ambos os gêneros. Fonte: autor

Alguns fatos que distinguem dos padrões usualmente praticados/pensados em relação às cores frontais foram observadas nesse resultado. Dentre as meninas, a cor preta teve uma incidência de escolha maior do que cores tidas como preferidas, como o lilás e algumas combinações de rosa; o mesmo aconteceu com a cor branca, não muito usual para as armações infantis femininas. Em contrapartida, o frontal transparente, considerado uma opção discreta e neutra, foi pouco escolhido. Para os meninos, as cores grafite e marrom, comuns em armações masculinas, foram menos escolhidas que cores marcantes como o verde limão e vermelho. Desta forma, é possível observar que, em geral, as crianças estão dispostas a usar uma gama diferente de cores no frontal dos óculos sem se preocuparem, em grande parte das vezes, com a discrição. A variação de cores também demonstra que nem sempre o padrão adulto do produto é adotado pelas crianças, já que muitas cores escolhidas não são usuais na armação para adulto. Este fato é positivo pois fortalece o estilo e o segmento infantil do produto.

Na análise da escolha das cores por idade, para as meninas a cor Rosa, está presente na escolha de toda a faixa etária, sendo a mais escolhida entre 6 a 9 anos, perdendo sua predileção apenas com as meninas de 10 anos. As combinações, Branco e Azul, Preto e Vermelho estiveram dentre as cores prediletas das meninas mais velhas, mesmo não sendo tradicionalmente pensadas como cores do universo feminino infantil. Para os meninos, a cor Azul, mais escolhida, está presente em toda a faixa etária pesquisada, e lidera nas escolhas entre 6 a 9 anos. As cores seguintes, Preto e Prata, são predileções dos meninos mais velhos (9 e 10 anos). Cores menos usuais no produto, como vermelho e verde, estão presentes na escolha de todas as idades, mesmo que em menor incidência.

No item Acabamento da cor o conjunto das crianças prefere partes frontais com acabamento sólido. Na análise por gênero, a preferência predominante das meninas é pelo acabamento sólido $(18,4 \%)$ e degradé/translúcido $(12,1 \%)$ e para os meninos os acabamentos foscos $(22,7 \%)$ e sólidos $(14,2 \%)$, respectivamente. 0 acabamento da cor está relacionado ao material da armação; desta forma e mesmo havendo diferenças entre os gêneros, se observa que, para as meninas, na armação em plástico o acabamento de cor preferido é o sólido, seguida do degradé translúcido e nas armações de metal a escolha é por cores com acabamento metálico. Para os meninos, nas armações de plástico a opção majoritária é também pelo acabamento sólido, mas no metal a preferência é pelo acabamento fosco.

No item Formato da frente da armação, que está relacionado ao formato do aro, a preferência das meninas é equilibrada entre as formas Quadrado com lados arredondados (14,2\%), Quadrado (12,8\%) e Retangulares (12,1\%). Na preferência dos 
meninos, houve uma maior escolha pelo Quadrado (31,2\%), seguida do Quadrado com lados arredondados (11,3\%). Em relação à faixa etária, para as meninas o formato Quadrado com lados arredondados tem maior incidência, sendo a principal escolha entre 6 e 8 anos, enquanto o Quadrado e o Retangular têm maior incidência entre 9 e 10 anos. Para os meninos a predileção pelo Quadrado ocorre em todas as idades, sendo o mais escolhido em todas elas, com exceção dos 11 anos; a segunda preferência é o Quadrado com lados arredondados que aparece nesta posição em todas as idades, exceto aos 10 anos, no qual este não foi escolhido e nos 11 anos, quando foi o mais escolhido.

O equilíbrio da preferência feminina pelos três formatos pode indicar tanto que esta característica não é mais priorizada no momento da escolha, como que o público é simpatizante por diferentes formatos. Mesmo não estando entre os mais escolhidos, o formato ovalado também foi eleito, demonstrando assim a variabilidade de escolha das meninas. Nas opções disponíveis para os meninos, é importante mencionar que não havia frentes ovaladas, não sendo possível mensurar a afeição por este formato, porém a elevada escolha pelo formato Quadrado em relação ao Quadrado com lados arredondados mostra uma preferência acentuada por formatos angulares.

Em relação às características Aro, Ponte e Plaqueta do frontal observou-se que na totalidade das crianças, a preferência foi pelo Aro Inteiro $(60,3 \%)$ em relação ao Fio de Nylon (39,7\%); a Ponte Inteira (82,3\%) em relação à Soldada (17,7\%) e a ausência de Plaqueta na armação $(56,7 \%)$ em relação às armações com plaquetas $(43,3 \%)$.

Analisando os dados do Aro da armação por gênero, as meninas preferem o Aro inteiro e os meninos o Aro com Fio de Nylon. Para os meninos, dentre as duas opções, a diferença é pequena; ao contrario, para as meninas a porcentagem que optou pelo Aro inteiro (38,3\%) foi maior que pelo Fio de Nylon (13,5\%).

No item Ponte da armação, ambos os gêneros preferem modelo com Ponte Inteira em relação à Ponte Soldada, no conjunto das meninas há uma preferência de $40,4 \%$ e $11,3 \%$ e nos meninos $41,8 \%$ e $6,4 \%$, respectivamente. Tal resultado está relacionado à preferência por frontais produzidos em material plástico e em metal com uma chapa inteira, uma vez que a opção de ponte soldada está presente em modelos com aros separados, unidos pela ponte, através do processo de soldagem. A opção pela Ponte Inteira é positiva para as crianças, pois o frontal com ponte soldada já apresenta em sua constituição pontos frágeis, sendo mais propícia a quebra.

No item Plaqueta os gêneros apresentaram escolhas distintas, as meninas optam por frentes sem Plaqueta (38,3\% comparado com 13,5\%) e os meninos com Plaqueta $(29,8 \%$ comparado com $18,4 \%)$. A presença ou não da plaqueta tem relação com o material utilizado na parte frontal, uma vez que, a maioria dos frontais em plástico não possui esse componente ao contrário da maioria dos partes em metal.

\subsection{Itens referentes as hastes}

Analisando as características referentes às hastes, ou seja, a Composição, o Material e a Largura, foram observados que na totalidade dos participantes a preferência é por hastes inteiras $(61,7 \%)$, ou seja, em uma peça única ao invés de com ponteira (38,3\%). No item Material as crianças preferiram as produzidas em plástico $(47,5 \%)$ seguidas, respectivamente, por borracha $(17,1 \%)$ e metal/plástico $(16,3 \%)$ e no item Largura os mais escolhidos foram hastes de largura média $(71,6 \%)$. 
Na divisão por gêneros, a Composição da haste preferida pelas meninas é a inteira com escolha acentuada; para os meninos a escolha das com ponteiras foi maior. A preferência das crianças pelas hastes inteiras acarreta um ponto negativo ao produto, pois não possibilita que esta seja reduzida de tamanho; o que na maioria das vezes é possível fazer com as ponteiras de plástico ou metal, possibilitando um ajuste de tamanho.

No item Material da haste, as meninas preferem expressivamente o plástico $(38,8 \%)$ seguida da combinação metal e plástico $(10,6 \%)$, e os meninos a borracha $(15,6 \%)$ e a combinação metal e borracha $(10,6 \%)$. Analisando pela faixa etária pesquisada, o Plástico foi escolhido com maior freqüência, em todas as idades das meninas, seguida da combinação Metal e Plástico, dentre as idades de 7 a 10. Para os meninos, a Borracha está presente em todas as idades sendo também o preferido, exceto os de 9 anos, seguida da combinação Metal e Borracha, também com frequência equilibrada entre todas as idades, diferente do terceiro material, o Plástico, que apresentou uma incidência maior entre os meninos mais velhos, entre 9 e 10 anos.

No item Largura da haste, as meninas e os meninos preferiram os formatos com largura de haste mediana apresentando, na análise em conjunto, uma frequência de $33,3 \%$ e $38,3 \%$, respectivamente.

No item Quantidade de cores as meninas preferiram hastes com duas cores, enquanto os meninos de ambos os estados, preferiram hastes com apenas uma cor.

Em relação às Cores das hastes, observou-se predileção das meninas pelas cores Rosa e Roxo/Rosa, enquanto que a cor Marrom foi a mais escolhida pelos meninos. Na análise separada por idade para ambos os gêneros as preferências foram bastante diversas, o que demonstra uma boa aceitação da diversidade de cores, sem predileção discrepante. Para as meninas dentre as cores com maiores frequências o Rosa e o Roxo com Rosa são escolhidos em várias idades; a escolha pela combinação Branca e Azul se concentra nas idades mais de 9 e 10 anos. Para os meninos dentre as cores mais escolhidas, o Marrom tem maior predileção entre os mais novos enquanto o Preto e o Cinza pelos mais velhos(Figura 5).

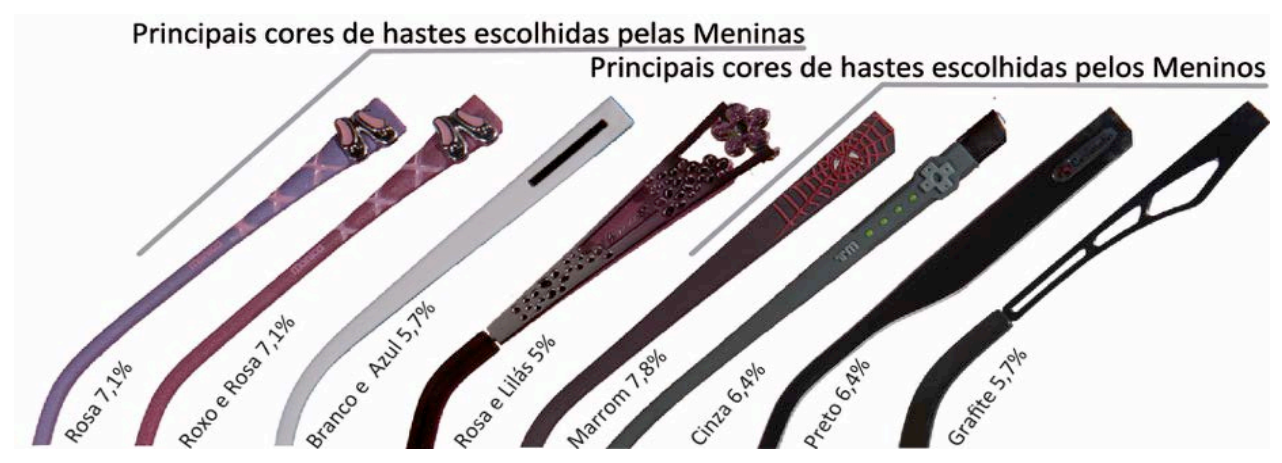

Figura 5 - Principais cores das hastes escolhidas por ambos os gêneros. Fonte: autor

As preferências de cores apresentaram algumas curiosidades, como a escolha elevada pela cor branca pelas meninas, mesmo essa não sendo tão presente nos produtos convencionados no universo feminino infantil. A combinação com a cor preta também foi bastante escolhida, igualando-se ao vermelho; ambas tiveram frequência maior que o prata, cor usual nos óculos, demonstrando surpresa devido à sobriedade 
da cor para o público. Dentre os meninos, as cores mais escolhidas são as sóbrias (preto, marrom e cinza); curiosamente, a cor azul foi pouco escolhida, assim como a cor prata com suas combinações; dessa forma, é possível afirmar que a maioria dos meninos assume uma postura mais conservadora em relação às cores das hastes.

O último item analisado são os Elementos das hastes, que são ornamentos da parte lateral dos óculos com formas que costumam influenciar na escolha do produto. $\mathrm{Na}$ análise separada por gênero, dentre as meninas, o elemento Sapatilha é o mais escolhido, seguido do Traço metálico, e dentre os meninos a mais escolhida é a haste Sem Detalhes, seguida da Bola de futebol (Figura 6).

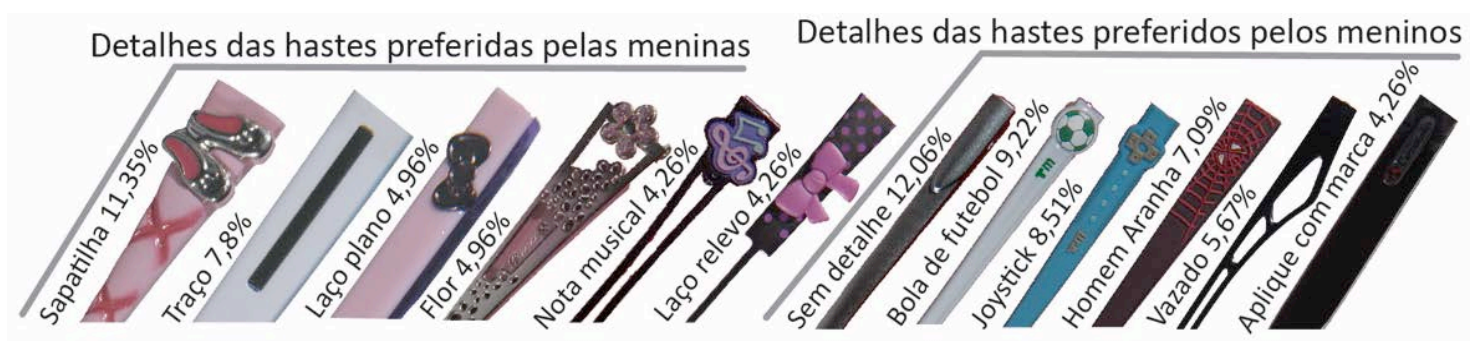

Figura 6 - Principais Elementos das hastes escolhidos por ambos os gêneros.

Fonte: autor

A escolha das meninas pela haste com elemento Sapatilha ocorre em todas as idades (6 a 10 anos) e apresenta detalhes minuciosos com relevo; já os seguintes elementos, traço metálico e laço sem relevo, são discretos e escolhidos pela maioria das meninas mais velhas (9 e 10 anos). Assim, é possível afirmar que hastes com detalhes e temática feminina são escolhidas por meninas de todas as faixa etárias; sendo os elementos mais discretos preferidos por meninas mais velhas. Diferente dos meninos, a escolha por hastes sem detalhes foi bastante baixa pelas meninas. Dentre as seis opções mais escolhidas, é possível observar que, duas possuem detalhes discretos e as outras possuem detalhes mais expressivos, o que indica que inexiste uma unanimidade pelo estilo de elementos escolhidos.

Para os meninos, a escolha mais acentuada por hastes sem detalhes, está presente em toda a faixa etária, porém, com maior presença nas idades mais velhas. É importante mencionar que estes componentes não possuem detalhes, mas contém formas e cores que, possivelmente, determinaram sua escolha. A haste do Homem Aranha (super-heroi) é preferida pelos meninos mais novos (6 a 8 anos), acreditandose por se tratar de um tema mais lúdico enquanto que, o Joystick (jogos/tecnologia) e Bola de futebol (esporte) são preferidos pelos mais velhos (9, 10 e 11 anos). Dentre os mais escolhidos, após a haste sem detalhe, foram a Bola de futebol, Joystick e HomemAranha, seguidas de dois modelos com elementos mais discretos. Assim é possível afirmar que, mesmo a maioria optando por discrição, quando trabalhados temáticas do universo infantil masculino,ocorre uma boa aceitação por esses usuários.

\subsection{Justificativas Escritas}

As justificativas escritas pelas crianças foram analisadas, computando-se as principais características mencionadas como elementos representantes e responsáveis pelas combinações escolhidas. Nos dados gerais apontados pelas crianças, a característica mais comentada é a Cor, com a frequência muito maior que as outras, 
seguida do Detalhe das hastes. A marca do produto foi mencionada por apenas um participante de cada gênero, sendo curiosamente um motivo quase que insignificante na escolha, mesmo com a presença de algumas marcas famosas dentre as partes apresentadas.

No conjunto feminino a característica mais comentada foi a Cor, sendo especificada algumas vezes a preferência nas da frente e da haste; em seguida, foi mencionado o Detalhe da haste e também do frontal; posteriormente, foi apontado o Formato em geral, seguido do Modelo, e uma pequena parcela comentou sobre o Material e do Acabamento da cor. No conjunto dos meninos a característica mais comentada é a Cor, mas diferente das meninas uma parcela maior especificou a escolha pela cor do frontal e da haste; em seguida, a preferência maior foi pelo Detalhe da haste, seguido do Formato e igualmente pelo Material, que foi mais comentado pelos meninos que pelas meninas. Vários meninos mencionaram a escolha do aro (inteiro/fio de nylon) e dois participantes mencionaram a resistência do produto, sendo que ambas características não foram mencionadas pelas meninas.

Observando os dados gerais das justificativas é possível afirmar que as características consideradas pelos meninos englobaram mais variáveis que as meninas; sendo as dos participantes masculinos mais específicas e detalhadas.

\section{RESULTADOS COMPLEMENTARES ÀS DOS DEMAIS STAKEHOLDERS}

$\mathrm{Na}$ etapa final da pesquisa, com os resultados prévios triangulados, foi possível observar os demais dados provenientes dos outros grupos pesquisados, que também tratavam das características formais das armações. Assim, as informações seguintes são complementares aos resultados descritos acima coletados com as crianças.

Nas justificativas escritas, as crianças indicam a cor e os detalhes como principais características na escolha do produto, e essa informação coincide com as características mencionadas pelos atendentes, que chamam mais atenção do público na ótica (cores e os desenhos/detalhes nas hastes).

A relação entre as patologias mais comuns que acometem as crianças e as características do produto foram mencionados pelos atendentes das óticas e pelos oftalmologistas. As patologias necessitam de tipos de lentes com características específicas que demandam armações com propriedades distintas para acomodá-las. Essas informações estão organizadas no quadro a seguir:

\begin{tabular}{|c|c|}
\hline $\begin{array}{l}\text { Patologias mais } \\
\text { comuns }\end{array}$ & Características da lente corretiva e da armação \\
\hline Miopia & $\begin{array}{l}\text { A lente possui o centro fino e a parte periférica grossa; assim, quanto maior o aro da } \\
\text { armação maior será a área da lente e maior destaque será dado às bordas grossas. } \\
\text { Uma armação com o aro menor reduzirá o peso e a espessura da lente a mostra. }\end{array}$ \\
\hline Astigmatismo & $\begin{array}{l}\text { A armação deve ter o formato para acomodar lentes retangulares ou quadrada, } \\
\text { evitando olhos ovalados para que não haja possibilidade da lente se movimentar } \\
\text { (girar) em um momento de limpeza, saindo, assim, do seu eixo. }\end{array}$ \\
\hline Hipermetropia & $\begin{array}{l}\text { Para uma hipermetropia alta, é recomendado formato de lentes arredondadas para } \\
\text { melhor optimização das lentes evitando, assim, modelos quadrados e ovalados. }\end{array}$ \\
\hline Estrabismo & $\begin{array}{l}\text { Para alguns casos são prescritas lentes bifocais, sendo aconselhável que o aro tenha } \\
\text { uma boa altura para que possa acomodar essas lentes, que necessitam de um } \\
\text { tamanho mínimo para serem eficazes. }\end{array}$ \\
\hline $\begin{array}{l}\text { Catarata } \\
\text { infantil }\end{array}$ & $\begin{array}{l}\text { A armação deve ser leve pois devido ao grau alto as lentes serão de espessura } \\
\text { grossa e consequentemente pesadas. }\end{array}$ \\
\hline
\end{tabular}


Em relação ao material do frontal, os oftalmologistas, os cuidadores e os atendentes das óticas indicam a preferência por um material rígido como o plástico injetado ou o acetato, devido à sua resistência, por entortarem menos e pela segurança no uso. O metal é considerado mais propício a entortar em caso de descuidos e com maior dificuldade de conserto, além de agregar plaquetas e parafusos que podem ser perigosas. A armação com este material pode ser indicada quando 0 uso é menos frequente ou na condição de um segundo óculos.

Em relação ao aro, a indicação dos oftalmologistas e atendentes das óticas, é que o mesmo seja completo, evitando modelos com fio de nylon e sem aro (lentes parafusadas), que podem comprometer a segurança no uso devido a maior exposição a quebra, principalmente se a criança só tiver um óculos.

A cor é o elemento do produto mais importante conforme indicado pelas crianças, assim os atendentes das óticas comentam que dentre as escolhas das crianças são observados produtos com cores compostas variadas; esta informação também é comentada pelos cuidadores que observam a variedade de cores escolhida.

Os elementos da haste são apontados como importantes pelos atendentes das óticas, os mesmos observam que para as crianças mais novas gostam de personagens, e as meninas também gostam de detalhes brilhosos. Para as crianças mais velhas, a marca do produto ganha maior importância na escolha.

\section{CONSIDERAÇÕES FINAIS}

O método realizado com as crianças possibilitou alcançar e validar o objetivo desejado de levantar alguns comportamentos e inclinação em relação as preferências das armações comercializadas atualmente. Os resultados não tinham a intenção de definir uma tendência do produto no momento e sim de observar algumas premissas e convicções convencionadas em relação ao produto e suas partes, bem como averiguar alguns padrões semelhantes entre as combinações; identificar as preferências consideradas mais importantes e mais atrativas pelo público definido. Dessa forma, mesmo contando com uma diversidade de produtos limitada foi possível alcançar resultados esperados, que representam os comportamentos e desejos deste público sendo mais estáveis que tendências temporais.

O método relatado no artigo, que foi estruturado para o objetivo desejado, consistiu em uma coleta de dados junto aos usuários, com a participação ativa dos mesmos construindo uma combinação de produto, com a posterior análise desses resultados. O mesmo princípio construtivo desse método pode ser replicado, sendo uma alternativa para outras pesquisas que buscam observar as preferências de produtos com a participação dos usuários ou dos stakeholders envolvidos.

Para a definição das diretrizes para o projeto de óculos infantil, os resultados acima coletados com as crianças a respeito das preferências formais do produto, complementaram as informações de caráter mais subjetivos alcançadas com o método do storytelling. Com esse conteúdo e os demais resultados proveniente dos métodos aplicados com os outros stakeholders foi realizada uma triangulação, possibilitando então a definição das diretrizes. 


\section{AGRADECIMENTOS}

À FAPESP (Fundação de Amparo à Pesquisa do Estado de São Paulo) pelo financiamento e apoio nessa pesquisa (Processo 2012/10910-1).

\section{REFERÊNCIAS}

ACERENZA, Franca. Eyewear: Gli Occhiali. 2ed. San Francisco: Chronicle Books, 1997.

BRASIL, Aline. De prótese a objeto de design. Revista AbcDesign, Curitiba, n. 15, p. 4-9, março, 2006.

FREEMAN, R. Edward. Strategic management: A stakeholder approach. Cambridge, England: Cambridge University Press, 2010.

GIACOMIN, Joseph. What is Human Centred Design?. In: CONGRESSO BRASILEIRO DE PESQUISA EM DESIGN, 10. 2012, São Luís - MA. Anais...São Luís: EDUFMA, 2012. P.148-161.

GOZLAN, Eric. Adaptação de óculos para crianças. Revista View, São Paulo, n.79, p.52, abril, 2007.

KRIPPENDORFF, Klaus. Propositions of Human-centeredness: A Philosophy for Design. In: DURLING, D.; FRIEDMAN, K.(Eds). Doctoral Education in Design: Foundations for the Future. Staffordshire: Staffordshire University Press, 2000. p.55-63.

KUMAR, Vijay. 101 Design Methods: A Structured Approach for Driving Innovation in Your Organization. Hoboken, New Jersey: John Wiley \& Sons, Inc., 2013.

MALDONADO, Tomás. Cultura, Sociedade e Técnica. São Paulo: Blucher, 2012.

PULLIN, Graham. Design meets disability. Massachusetts: The MIT Press, 2009.

VEYRAT, Nicolas; BLANCO, Eric.; TROMPETTE, Pascalle. Social Embodiment of Technical Devices: Eyeglasses Over the Centuries and According to their Uses. Mind, Culture, and Activity, v.15, n.3, p.185-207, 2008. 